\title{
Visualization of Acetylcholine in the Mouse Brain by a Combination of Immunohistochemistry with Ionic Fixation
}

\author{
Jun-ichi Tanaka, Kayo Mishiro, Jun Watanabe and Shinsuke Kanamura \\ Department of Anatomy, Kansai Medical University, Moriguchi, Osaka 570
}

Received for publication February 2, 1995 and in revised form May 20, 1995

\begin{abstract}
Although acetylcholine (Ach) is an important neurotransmitter, there is no adequate histochemical method to detect Ach in tissue sections. We therefore developed a method to visualize the localization of Ach in tissue sections by a combination of immunohistochemistry with ionic fixation. Brains of mice, perfused with $4 \%$ formaldehyde and $5 \%$ phosphomolybdic acid (PMA) in $0.1 \mathrm{M}$ phosphate buffer (pH 7.4) under sodium pentobarbital anesthesia, were removed and immersed quickly in boiling PMA solution for $5 \mathrm{~min}$. Frozen sections were cut and soaked
\end{abstract}

in a buffer containing 5\% PMA at $4^{\circ} \mathrm{C}$ for $30 \mathrm{~min}$, and immersed in a buffer containing bovine serum albumin at $4^{\circ} \mathrm{C}$ for $1 \mathrm{hr}$. Then the sections were incubated with anti-Ach antibody at $4^{\circ} \mathrm{C}$ for $12 \mathrm{hr}$. Subsequently, the immunoreaction due to Ach was visualized by the peroxidase-antiperoxidase method. Nerve cells in the brain sections from the interpeduncular nucleus of the cerebrum and bipolar cells in the multiform layer of the cerebral cortex were immmunohistochemically stained with the anti-Ach antibody.

Key words: Acetylcholine, Immunohistochemistry, Anti-acetylcholine antibody, lonic fixation, Cerebrum, Mouse

\section{Introduction}

Acetylcholine (Ach) is one of the most important neurotransmitters in the central and peripheral nervous system in vertebrates. The organization of cholinergic neurons has been examined by visualizing acetylcholinesterase (AchE) or choline acetyltransferase (ChAT). However, the usage of AchE as a marker of cholinergic neurons has been questioned, because AchE is present in noncholinergic neurons as well as cholinergic neurons [1, $2,6,10]$. On the other hand, immunohistochemical detection of ChAT is a good method to visualize cholinergic neurons $[1,2,4,8-12]$. However, immunohistochemical detection of ChAT involves complicated purification of the enzyme to produce anti-ChAT antibody, and requires numerous specificity tests. Furthermore, application of the raised antibody is restricted to species closely related to the species from which the enzyme was obtained [5]. Thus, although immunohistochemistry for ChAT is helpful, the most desirable method is direct visualization of Ach [5].

Recently, specific anti-Ach antibodies have been rais-

Correspondence to: Dr. Shinsuke Kanamura, Department of Anatomy, Kansai Medical University, 10-15 Fumizono-cho, Moriguchi, Osaka 570, Japan. ed for radio- or enzyme immunoassay [5, 14]. Geffard et al. [5] produced anti-choline-glutaryl-polypeptide antibodies and visualized Ach in tissue sections with the antibodies by immunohistochemistry. To retain Ach molecules in the sections, Geffard et al. [5] fixed the sections with a high concentration of glutaraldehyde $(0.5 \mathrm{M})$ and allyl alcohol $(0.5 \mathrm{M})$ at a very high $\mathrm{pH}(\mathrm{pH} 11)$. This method has not been used by any other investigators. Ach cannot be directly fixed with standard fixatives such as aldehydes or alcohols, since Ach molecule is an ester of choline. Furthermore, Ach decays very rapidly by the action of AchE in mammals [13]. To visualize Ach in mammalian tissue sections, therefore, a potent fixation method for Ach and a technique to prevent the postmortal decay of Ach due to AchE should be required.

Tsuji and co-workers [17] showed the localization of Ach-"like" cations in tissue sections using ionic fixation with molybdic or tungstic heteropolyanions as a precipitating agent of quaternary ammonium cations such as choline and Ach, although it is nuclear whether these heteropolyanions bind specifically Ach. Tsuji $[15,16]$ also detected the localization of the cations or ${ }^{3} \mathrm{H}$-Ach derived from ${ }^{3} \mathrm{H}$-choline as electron dense precipitates in the neuro-muscular junction at the electron microscopic level.

To establish a specific and reproducible method to 
visualize Ach in sections, we examined the effect of fixation on the binding of anti-Ach antibody to Ach molecules spotted onto nitrocellulose membrane. Then, we applied the ionic fixation to immunohistochemical detection of Ach in sections cut from the mouse brain.

\section{Materials and Methods}

\section{Dot binding assay on nitrocellulose membrane}

Ach was dissolved with distilled water and serially diluted with distilled water. Aliquots $(1 \mu \mathrm{l})$ of the diluents were applied onto nitrocellulose (NC) membranes (pore size $0.22 \mu \mathrm{m}$, MSI, Westboro, MA) with precision micropipets as described previously [18], and air-dried at $25^{\circ} \mathrm{C}$ for $10 \mathrm{~min}$. The membranes were preincubated in phosphate buffered saline (PBS), $5 \%$ (w/v) phosphomolybdic acid (PMA) or $0.1 \mathrm{M}$ phosphate buffer containing $0.5 \mathrm{M}$ allyl alcohol plus $0.5 \mathrm{M}$ glutaraldehyde for $30 \mathrm{~min}$ at $4^{\circ} \mathrm{C}$.

Then, the membranes preincubated with PBS or PMA were immersed in 5\% PMA for $10 \mathrm{~min}$ at room temperature and washed with PBS ( $5 \mathrm{~min} \times 3$ times). Some of the washed membranes were stained with $5 \%(w / v)$ tin chloride at room temperature for $5 \mathrm{~min}$ according to the method to Tsuji [15]. The membranes preincubated with allyl alcohol plus glutaraldehyde were washed with PBS as above.

The washed membranes were immersed in PBS containing $1 \%$ bovine serum albumin (BSA) for $1 \mathrm{hr}$ at $4^{\circ} \mathrm{C}$, incubated in PBS containing anti-Ach antibody (Chemicon, Temecula, CA; diluted 1:200) at $4^{\circ} \mathrm{C}$ for $1 \mathrm{hr}$, and washed again with PBS. The incubated and washed membranes were processed according to the peroxidaseantiperoxidase (PAP) method using a PAP kit (HISTOFINE, Seikagaku Kogyo, Tokyo, Japan), washed with PBS, and stained with 3,3'-diaminobenzidine. In addition, aliquots of brain homogenates prepared as described below were applied onto NC membranes and processed for immunohistochemistry as above.

Ach, choline, BSA, myosin, physostigmine or phosphatidylcholine (1 $\mu \mathrm{g} / \mathrm{spot})$ was applied onto NC membranes and air-dried as above. The membranes were preincubated with $5 \%$ PMA for $5 \mathrm{~min}$ at 4 or $97^{\circ} \mathrm{C}$ and washed with PBS ( $5 \mathrm{~min} \times 3$ times). Some membranes were stained with $5 \%$ tin chloride, while the remaining membranes were stained with anti-Ach antibody as above.

\section{Immunohistochemistry for acetylcholine (Ach)}

Twenty male ddY mice, three months old, were used. The animals were fed laboratory chow and water prior to the experiments, and anesthesized by an intraperitoneal injection of sodium pentobarbital $(80 \mathrm{mg} / \mathrm{kg}$ body weight). Under anesthesia, brains of the animals were transcardially perfused with $0.1 \mathrm{M}$ phosphate buffer ( $\mathrm{pH} 7.4$ ) containing $4 \%$ formaldehyde (FA) or a buffer containing $4 \%$ FA plus 5\% PMA for $10 \mathrm{~min}$. The brains were removed, sliced transversely (about $1 \mathrm{~mm}$ in thickness) and immersed in boiling 5\% PMA for $5 \mathrm{~min}$. Some slices were immersed in 5\% PMA and heated with a microwave oven (NEM-340, Matsushita, Kadoma, Japan; $2450 \mathrm{MHz}, 500 \mathrm{~W}$ ) for $5 \mathrm{~min}$. The slices were immersed in ice-cold PMA for $30 \mathrm{~min}$, frozen in dry-ice acetone, and cut at $20 \mu \mathrm{m}$ thick in a cryostat. The sections were immersed in ice-cold PBS containing 5\% PMA for $30 \mathrm{~min}$ and further immersed in PBS containing 1\% BSA or diluted normal goat serum (1: 10 with PBS) for $1 \mathrm{hr}$ at $4^{\circ} \mathrm{C}$. Then, the sections were incubated for $12 \mathrm{hr}$ with anti-Ach antibody (Chemicon; diluted $1: 25-1: 400$ with PBS) at $4^{\circ} \mathrm{C}$, and washed with PBS (5 min $\times 3$ times). The incubated and washed sections were processed according to the PAP method, washed again with PBS, stained with 3,3'-diaminobenzidine, and observed in a microscope (Nikon XF). For control experiments, sections incubated with normal rabbit serum or PBS instead of the anti-Ach antibody, and those incubated with pre-absorbed anti-Ach antibody were processed as mentioned above.

\section{Immunohistochemistry for choline acetyltransferase (ChAT)}

Five male ddY mice, 3-5 months old, were used. Under sodium pentobarbital anesthesia $(80 \mathrm{mg} / \mathrm{kg}$, ip), brains of mice were transcardially perfused with ice-cold saline for $30 \mathrm{sec}$ followed by ice-cold 4\% FA in $0.1 \mathrm{M}$ phophate buffer $(\mathrm{pH} \mathrm{7.4)}$ for $15 \mathrm{~min}$. The fixed brains were removed, immersed in the same fixative for $3 \mathrm{hr}$ at $4^{\circ} \mathrm{C}$, and transferred to $20 \%$ sucrose for 2 days at $4^{\circ} \mathrm{C}$. The brains were frozen, cut at $20 \mu \mathrm{m}$, immersed in ice-cold normal goat serum (diluted 1:10 with PBS) for $2 \mathrm{hr}$ at $4^{\circ} \mathrm{C}$, and then, incubated for $12 \mathrm{hr}$ with anti-ChAT antibody (Chemicon; diluted 1: 1,000 with PBS) at $4^{\circ} \mathrm{C}$. The sections were washed with PBS and processed for PAP reaction.

\section{Biochemical methods}

Twenty male ddY mice, 3-5 months old, were used. Under sodium pentobarbital anesthesia $(80 \mathrm{mg} / \mathrm{kg}$, i.p.), brains of five animals were transcardially perfused with ice-cold PBS containing $1 \mathrm{mM}$ physostigmine, PBS alone or 5\% PMA for $5 \mathrm{~min}$, and then removed and cut into slices. Some slices were immersed in boiling PBS or 5\% PMA for $5 \mathrm{~min}$, and the remaining slices were immersed in ice-cold PBS or 5\% PMA. Then brains or the brain slices were homogenized with 20 volumes of $0.25 \mathrm{M}$ sucrose and centrifuged at $1,000 \mathrm{~g}$ for $15 \mathrm{~min}$ at $4^{\circ} \mathrm{C}$. Aliquots of the resulting supernatants were applied onto a nitrocellulose membrane as mentioned above or used for the measurement of AchE activity. AchE activity was measured by the method of Ellman et al. [3] using Ach iodide as a substrate. The variations of absorbance at $412 \mathrm{~nm}$ were measured at $30 \mathrm{sec}$ intervals in a Hitachi U-3,200 spectrophotometer. 


\section{Results}

\section{Dot binding assay}

When Ach-blotted NC membranes were immersed in 5\% PMA, white precipitates were formed at blotted spots in all the blotted membranes. The precipitates turned blue in color after immersion in the tin chloride solution. No stained spots were seen in the membranes preincubated in PBS instead of PMA (Fig. 1).

The immuno-stained spots were seen in the membrane preincubated in PMA solution but not in the membranes preincubated in PBS (Fig. 1). No immuno-stained spot was found in the membrane preincubated with allyl alcohol and glutaraldehyde.

Ach, BSA, myosin, or physostigmine blotted on NC membrane was positively stained with tin chloride after the immersion of hot or cold 5\% PMA (Fig. 2), although phosphatidylcholine was not stained, and choline was stained very slightly. Ach immobilized on the membrane was stained with anti-Ach antibody, whereas choline, BSA, myosin or phosphatidylcholine was not stained with the anibody. Very weak immunostaining was occasionally seen in spots of physostigmine.

When homogenate from brains perfused without PMA was immobilized on NC membrane and stained with anti-Ach antibody, the spots were not stained (Fig. 3, Table 1). However, homogenate from brains perfused with PMA showed a positive immunoreaction. The reaction was strong when the membranes were immersed in boiling PMA solution followed by cold PMA solution. The reaction was moderate when the membranes were immersed in boiling PMA followed by PBS or immersed in boiling PBS followed by cold PMA. The reaction was weak when the membranes were immersed in boiling PBS followed by cold PBS.

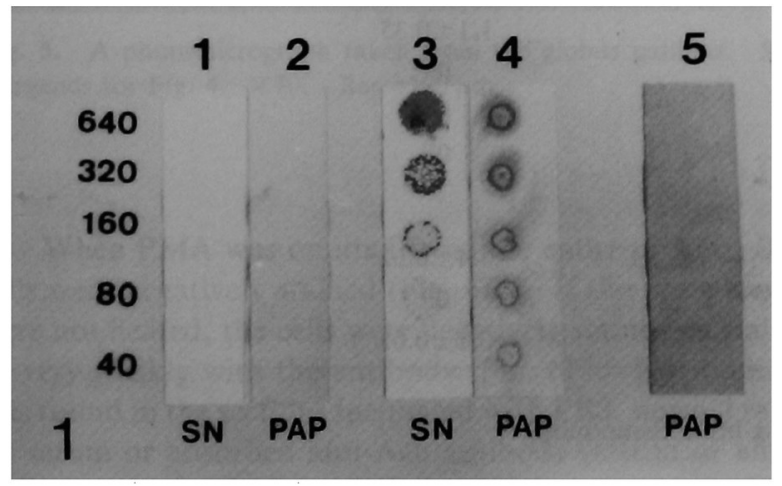

Fig. 1. Dot blot analysis of acetylcholine (Ach) spotted on nitrocellulose (NC) membranes. Lanes 1 and 2, preincubated in phosphate buffered saline (PBS); lanes 3 and 4, preincubated in 5\% phosphomolybdic acid (PMA); lane 5, immersed in $0.5 \mathrm{M}$ allyl alcohol plus $0.5 \mathrm{M}$ glutaraldehyde. Lanes 1 and 3, stained with tin chloride (SN); Lanes 2, 4 and 5, stained with anti-Ach antibody according to the peroxidase-anti-peroxidase (PAP) method. Numbers at the left side indicate the amount of Ach applied (ng).

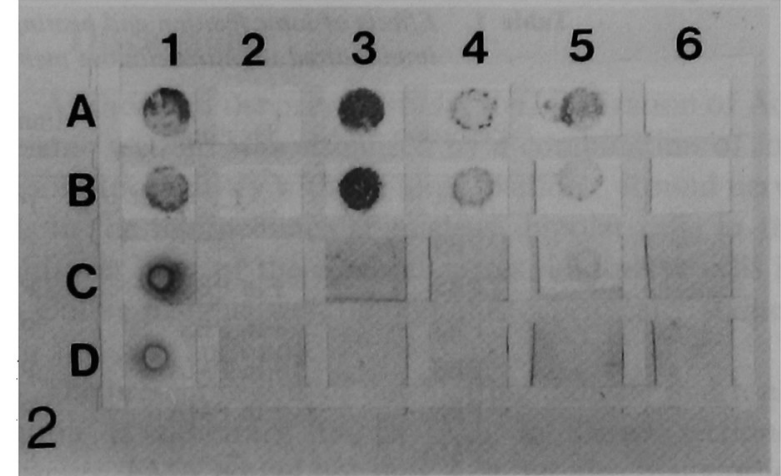

Fig. 2. Dot blot analysis of Ach (column 1), choline (column 2), bovine serum albumin (BSA) (column 3), rat myosin (column 4), physostigmine (column 5) and phosphatidylcholine (column 6) spotted on NC membranes ( $1 \mu \mathrm{g} / \mathrm{spot})$. The spotted membranes were dried, preincubated in $5 \%$ PMA at $4^{\circ} \mathrm{C}$ (lines $\mathrm{A}$ and $\mathrm{C}$ ) or $97^{\circ} \mathrm{C}$ (lines $B$ and $D$ ), and processed for the tin chloride (SN) staining (lines A and B) or for the detection of Ach according to the PAP method (lines $\mathrm{C}$ and $\mathrm{D}$ ).

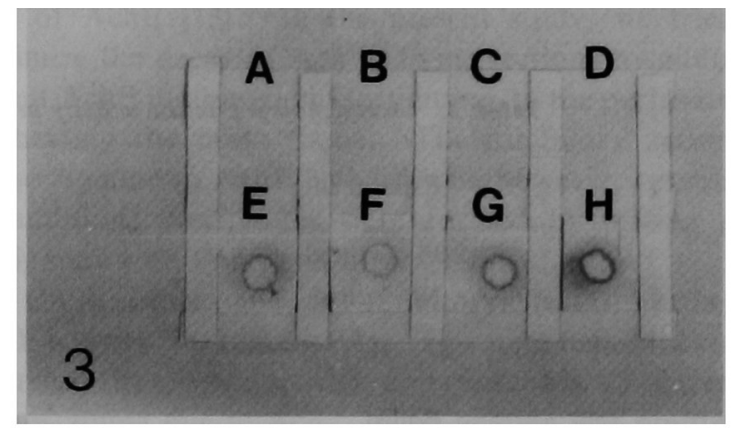

Fig. 3. Dot blot analysis of brain homogenate spotted on NC membrane. Homogenates from PBS-perfused brains (A-D) or those from PMA-perfused brains (E-H) were applied onto NC membrane (50 $\mu \mathrm{g}$ tissue/spot). Membranes were boiled in PBS (A, B, E, F) or 5\% PMA (C, D, G, H) and immersed in cold PBS (A, C, F, G) or cold 5\% PMA (B, D, E, H). See Table 1 for further explanation.

AchE activity in homogenates from PBS-perfused brains was high, and the activity remained unchanged for $2 \mathrm{hr}$ if the homogenates were kept at $4^{\circ} \mathrm{C}$ in $0.25 \mathrm{M}$ sucrose (Table 2). The activity was abolished in homogenates from boiled brains. The activity was very low in homogenates from physostigmine-perfused brains, but it increased gradually when the homogenates were kept at $4^{\circ} \mathrm{C}$ in $0.25 \mathrm{M}$ sucrose. The activity was very low when brains were immersed in boiling water or heated in a microwave oven by continuous microwave irradiation ( $500 \mathrm{~W}$ for $5 \mathrm{~min}$ ). However, after the pulse irradiation of microwave to brains in ice-cold PBS $(500 \mathrm{~W}, 10 \mathrm{sec}$ on $/ 20 \mathrm{sec}$ off cycle) for $15 \mathrm{~min}$, the activity was not very low (1.4 $\pm 0.59 \mu \mathrm{moles} / \mathrm{mg}$ brain $/ \mathrm{min})$.

\section{Immunohistochemical results}

Cholinergic neurons which have been identified by 
Table 1. Effects of ionic fixation and heating on immunoreactivity of acetylcholine from mouse brain immobilized on nitrocellulose membrane ${ }^{1)}$

\begin{tabular}{ccccc}
\hline Perfusion & Heating & $\begin{array}{c}\text { Immersion } \\
\text { after heating }\end{array}$ & $\begin{array}{c}\text { Intensity of } \\
\text { staining }\end{array}$ & Spot in Fig. 3 \\
\hline PBS & - & PBS & Negative & - \\
PBS & - & PMA & Negative & - \\
PBS & +in PBS & PBS & Negative & A \\
PBS & +in PBS & PMA & Negative & B \\
PBS & +in PMA & PBS & Negative/Trace & C \\
PBS & +in PMA & PMA & Negative/Trace & D \\
PMA & - & PBS & Trace & - \\
PMA & - & PMA & Weak/Trace & - \\
PMA & tin PBS & PMA & Moderate & E \\
PMA & +in PBS & PBS & Weak/Moderate & F \\
PMA & +in PMA & PBS & Moderate & G \\
PMA & +in PMA & PMA & Strong & H \\
\hline
\end{tabular}

"Homogenate from brains perfused with phosphate buffered saline (PBS) or $5 \%$ phosphomolybdic acid (PMA) were applied onto nitrocellulose membranes. Some membranes were boiled in 5\% PMA solution or PBS for $5 \mathrm{~min}$. Then the membranes were immersed in ice-cold 5\% PMA or PBS for $30 \mathrm{~min}$ and processed for immunodetection of acetylcholine acccording to the peroxidase-antiperoxidase method.

Table 2. Acetylcholine esterase activity in mouse brain perfused with PBS or I mM physostigmine)

\begin{tabular}{lcc}
\hline Experiment & $\begin{array}{c}\text { Minute after } \\
\text { homogenize }\end{array}$ & $\begin{array}{c}\text { Activity } \\
(\mu \text { moles/mg brain/min) }\end{array}$ \\
\hline PBS-perfused & 10 & $3.3 \pm 0.45$ \\
Not boiled & 30 & $3.4 \pm 0.51$ \\
& 120 & $3.2 \pm 0.55$ \\
Boiled & 10 & $0^{2)}$ \\
& 30 & $0^{2)}$ \\
& 120 & $0^{2)}$ \\
Physostigmine-perfused & & \\
Not boiled & 10 & $0.2 \pm 0.08$ \\
& 30 & $0.3 \pm 0.11$ \\
Boiled & 120 & $1.1 \pm 0.35$ \\
& 10 & $0^{2)}$ \\
& 30 & $0^{2)}$ \\
Whole brain (not perfused) & 120 & $0^{2)}$ \\
Not boiled & & \\
Boiled & 120 & $3.4 \pm 0.62$ \\
Heated with microwave & 120 & $0^{2)}$ \\
\end{tabular}

1) Values are means \pm S.E. for five measurement.

2) Lower than the limit of sensitivity ( $>0.03 \mu$ moles $/ \mathrm{mg}$ brain tissue $/ \mathrm{min}$ ).

3) Immersed in boiling water instead of boiling PBS.

ChAT immunohistochemistry in nerve cells of the interpeduncular nucleus, those of the cerebral cortex, and those of the globus pallidus were examined. When the brains perfused with buffered 4\% FA containing 5\% PMA were stained with anti-Ach antibody diluted $1: 200$ or
$1: 400$, many small round cells in the interpeduncular nucleus (Fig. 4), cell bodies and processes of some neurons in the globus pallidus (Fig. 5), and bipolar cells scattered in the multiform layer of the cerebral cortex (Fig. 6A-D) were positively stained. 


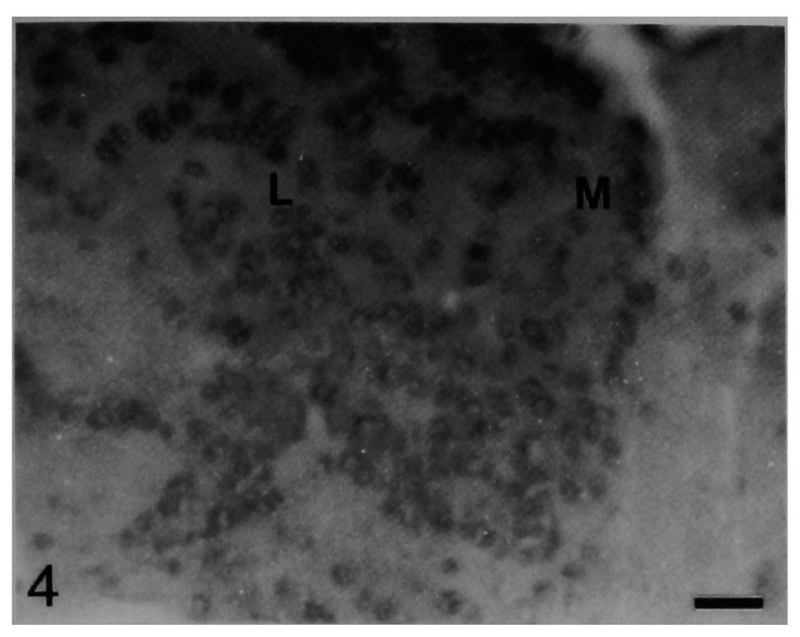

Fig. 4. A photomicrograph taken from the interpeduncular nucleus of mice after immunohistochemical detection of Ach. Brains were perfused with buffered $4 \%$ formaldehyde containing $5 \%$ PMA, sliced and boiled in 5\% PMA. Frozen sections cut from the slices were immersed in cold 5\% PMA and processed for the immunodetection of Ach with anti-Ach antibody (diluted 1: 400) according to the PAP method. M: medial region, L: lateral region. $\times 70 . \quad B a r=100 \mu \mathrm{m}$.

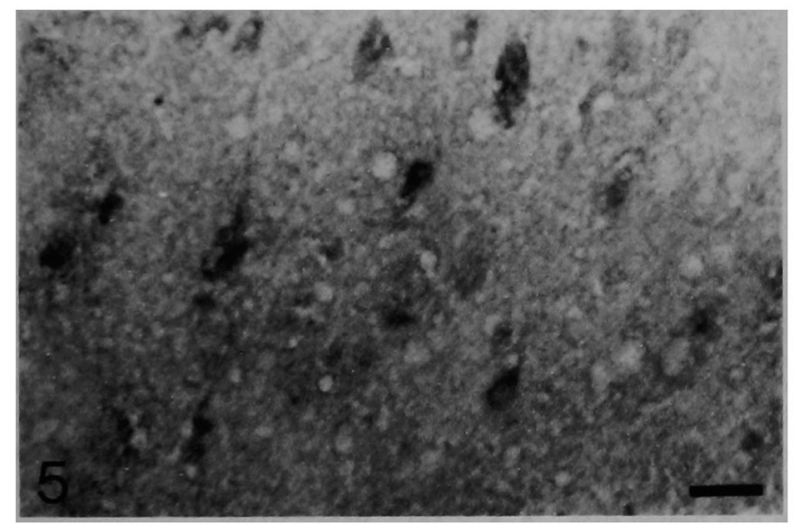

Fig. 5. A photomicrograph taken from the globus pallidus. See legends for Fig. 4. $\times 70 . \quad \mathrm{Bar}=100 \mu \mathrm{m}$.

When PMA was omitted from the entire process, the cells were negatively stained (Fig. 6E). If the brain slices were not heated, the cells were negatively stained or stained very weakly with the antibody (Fig. 6F). No staining was found in the sections incubated with PBS, normal rabbit serum or absorbed anti-Ach antibody instead of antiAch antibody. When a high concentration of anti-Ach antibody $(1: 50$ or $1: 25)$ was used, a strong background staining was observed, and the staining intensity of the positive cells did not increase. When the sections cut from the brains fixed with allyl alcohol and glutaraldehyde were incubated with the antibody, no positive cells were found while background staining was strong.

\section{Discussion}

As shown in the present study, the localization of Ach in tissue sections was visualized by a combination of immunohistochemistry with the ionic fixation. Round nerve cells in the interpeduncular nucleus, bipolar cells in the multiform layer of the cerebral cortex, and nerve cells in the globus pallidus were immunohistochemically stained with anti-Ach antibody.

The present results of dot blotting indicate that ionic fixation is necessary to fix Ach in tissue sections. However, PMA bound not only Ach but also many other substances. Ach-PMA complex bound anti-Ach antibody, whereas the binding of the antibody to BSA-PMA or myosin-PMA complex was negligible. Furthermore, the ionic fixation could not effectively fix choline and phosphatidylcholine. Therefore, the binding of anti-Ach antibody to Ach in the sections fixed by PMA is highly specific.

The decay of Ach after death occurs rapidly in mammals and birds [13]. The decay is primarily due to the action of AchE [13]. In the present study, we tried to minimize the decay of Ach in tissue sections by adding a potent AchE inhibitor, physostigmine, to the perfusate, or by heating the brain tissue. The inhibitory action of physostigmine to AchE activity was, however, reversible. In addition, precipitates were formed by mixing physostigmine with PMA solution.

On the other hand, the inhibitory effect of heating on AchE activity was remarkable. This treatment blocked irreversibly the enzyme activity, and resulted in a positive immunostaining due to Ach. If the heating was omitted, a negligible or very weak immunoreaction was seen in membranes and sections. When Ach in mammalian or avian tissue sections is to be visualized, it is therefore necessary to prevent the decay of Ach by heating tissues. However, this treatment probably destroys many other neurotransmitters and enzyme molecules. The present technique is thus inadequate for examining the co-localization of neurotransmitters in single neurons. In the present study, we failed to detect Ach and ChAT in the same sections or adjacent sections cut from the same brain slices.

Geffard et al. [5] produced anti-choline antibodies using choline-glutaryl-polypeptides as antigens, and applied these antibodies to allyl alcohol plus glutaraldehyde-fixed tissue sections to detect Ach. However, anti-Ach antibody used in the present study did not bind cholinergic neurons in allyl alcohol plus glutaraldehyde-fixed sections, and a strong nonspecific reaction was found in the sections. Similar results were obtained in Ach-blotted NC membranes. In these sections or membranes, Ach is desacetylated and transesterified [5]. This fact suggests that the sections and membranes contained no intact Ach molecules. This may be a reason for the negative staining of cholinergic neurons in allyl alcohol plus glutaraldehydefixed sections in the present study. The strong nonspecific reaction found in allyl alcohol plus glutaraldehyde-fixed 


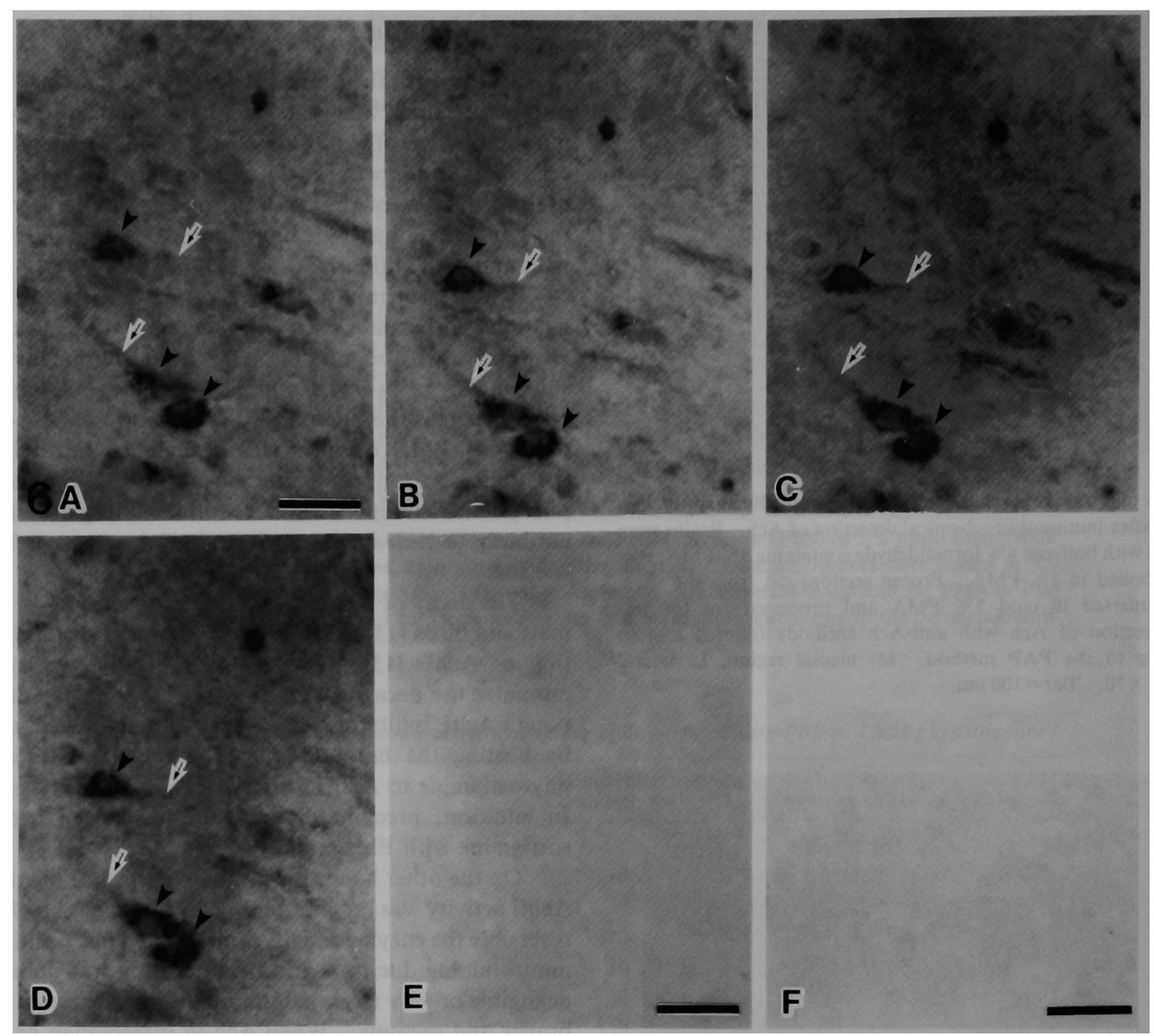

Fig. 6. Photomicrographs taken from a portion of the multiform layer of the cerebral cortex. A-D: Through-focus images of a section containing Ach-positive cells. The section cut from a brain slice boiled in 5\% PMA was further immersed in cold 5\% PMA and processed for the immunodetection of Ach with anti-Ach antibody (diluted 1:200) by the PAP method. Arrowheads indicate Ach-positive cell bodies, and arrows show Ach-positive processes. E: A portion of the multiform layer in the section processed as above, except that PMA was omitted from the entire process. F: A portion of the layer in the section cut from non-heated slice. A-F $\times 220$. Bars $=50 \mu \mathrm{m}$.

sections or membranes is probably due to the effect of a high concentration of glutaraldehyde.

Immunohistochemical detection of ChAT is a good and sensitive method to visualize cholinergic neurons $[1,2$, 8-12]. However, Hoover et al. [8] found that Ach content and ChAT content did not always show proportional variations in many areas in the rat brain. Thus, there is a possibility that the ChAT reaction is not restricted in cholinergic neurons. Goldberg and Hanin [6] showed that ChAT was present not only in cholinergic neurons but also in other cells in the brain, for example endothelial cells.

In the present results, cell bodies and processes of cholinergic neurons were stained with anti-Ach antibody. However, although the number of Ach-positive cell bodies appeared to be similar to that of ChAT-positive cell bodies, the number of Ach-positive processes was somewhat smaller than that of ChAT-positive processes. It is possible that the present method only visualizes processes of cholinergic neurons containing large amounts of Ach. If so, the physiological status of cholinergic neurons may be examined by combining the present method with ChAT immunohistochemistry. Another possibility is that the decay or efflux of Ach in processes occurs more rapidly than that occurs in cell bodies.

In the present study, we examined cholinergic neurons in the interpeduncular nucleus, those in the multiform layer of the cerebral cortex, and those in the globus pallidus. In addition to these regions, we also found Achpositive cell bodies in the striatum, median septum, substantia innominata, median habenular nucleus, dorsolateral tegmental nucleus and hippocampus in the mouse brain (unpublished results). Ach-positive processes were 
seen in the renticular nucleus and substantia nigra in addition to the above-mentioned regions, although the stained fibers were less frequent than ChAT-positive fibers. Small dot-like structures, less than $2 \mu \mathrm{m}$ in diameter, in the lenticular nucleus and corpus amygdaloideum were lightly stained with anti-Ach antibody, suggesting that these portions receive cholinergic innervation. The relation between these Ach-positive cells and ChAT-positive cells is now being examined.

\section{References}

1. Amaral, D. G. and Bassett, J. L.: Cholinergic innervation of the monkey amygdala: An immunohistochemical analysis with antisera to choline acetyltransferase. J. Comp. Neurol. 281; 337-361, 1989.

2. Eckenstein, F. and Sof roniew, M. V.: Identification of central cholinergic neurons containing both choline acetyltransferase and acetylcholinesterase and of central neurons containing only acetylcholinesterase. J. Neurosci. 3; 2286-2291, 1983.

3. Ellman, G. L., Courtney, K. D., Andres, V. Jr. and Featherstone, R. M.: A new and rapid colorimetric determination of acetylcholinesterase activity. Biochem. Pharmacol. 7; 88-95, 1961.

4. Fibiger, H.C.: The organization and some projections of cholinergic neurons of mammalian forebrain. Brain Res. Rev. 4; 327-388, 1982.

5. Geffard, M., McRae-Degueurce, A. and Souan, M. L.: Immunohistochemical detection of acetylcholine in the rat central nervous system. Science (Washington) 229; 77-79, 1985.

6. Goldberg, A. M. and Hanin, I.: Biology of Cholinergic Function. Raven Press, New York, 1976.

7. Hoover, D. B., Muth, E. A. and Jacobowitz, D. M.: A mapping of the distribution of acetylcholine, choline acetyltransferase and acetylcholinesterase in discreet areas of rat brain. Brain Res. 153; 295-306, 1978.

8. Ichikawa, T. and Hirata, Y.: Organization of choline acetyltransferase-containing structures in the forebrain of the rat. J. Neurosci. 6; 281-292, 1986.

9. Kimura, H., McGeer, P. L., Peng, J. H. and McGeer, E. G.: The central cholinergic system studied by choline acetyltransferase immunochemistry in the cat. J. Comp. Neurol. 200; 151-201, 1981.

10. Levey, A. I., Wainer, B. H., Mufson, E. J. and Measulam, M.M.: Co-localization of acetylcholinesterase and choline acetyltransferase in the rat cerebrum. Neuroscience 9; 9-22, 1983.

11. McGeer, P. L., McGeer, E.G., Singh, V.K. and Chase, W. H.: Choline acetyltransferase localization in the central nervous system by immunohistochemistry. Brain Res. 81; 373379, 1974.

12. Mesulam, M.-M., Mufson, E. J., Levey, A. I. and Wainer, B. H.: Cholinergic innervation of cortex by the basal forebrain: Cytochemistry and cortical connections of the septal area, diagonal band nuclei, nucleus basalis (substantia innominata), and hypothalamus in the rhesus monkey. J. Comp. Neurol. 214; 170-197, 1983.

13. Molinengo, L. and Francia, P.: Postmortal decay of acetylcholine levels in the spinal cord of rat, chicken and frog. Neurosci. Lett. 45; 181-185, 1984.

14. Spector, S., Felix, A., Semenuk, G. and Finberg, J. P. M.: Development of a specific radioimmunoassay for acetylcholine. J. Neurochem. 30; 685-689, 1978.

15. Tsuji, S.: Electron microscopical autoradiography of $\left[{ }^{3} \mathbf{H}\right]$ choline fixed by phosphomolybdic acid in the motor nerve terminal. Neurosci. Lett. 45; 151-156, 1984.

16. Tsuji, S.: Cryoultramicrotomy of unfixed tissues: Simultaneous transferance, "ionic fixation" and negative staining of the sections by means of silicotungstic acid. Cell. Mol. Biol. 32; 93-97, 1986.

17. Tsuji, S., Alameddine, H. S., Nakanishi, S. and Ohoka, T.: Molybdic and tungstic heteropolyanions for "ionic fixation" of acetylcholine in cholinergic motor nerve terminals. Histochemistry 77; 51-56, 1983.

18. Watanabe, J., Kanai, K. and Kanamura, S.: Measurement of NADPH-ferrihemoprotein reductase content in sections of liver. J. Histochem. Cytochem. 39; 1635-1643, 1991. 